${ }^{1}$ Dr. Öğr. Üyesi, Haliç Üniversitesi, Hemşirelik Yüksekokulu, İstanbul,Türkiye

${ }^{2}$ Uzman Hemşire, T.C. Sağlık Bakanlığı İstanbul Bakırköy Prof. Dr. Mazhar Osman Ruh Sağlığı ve Sinir Hastalıkları Eğitim ve Araştırma Hastanesi, İstanbul, Türkiye

${ }^{3}$ Dr. Hemşire, istanbul î Sağlık Müdürlügüü İstanbul, Türkiye

Sorumlu Yazar: Gülcan Kendirkıran, Dr. Öğr. Üyesi, Haliç Üniversitesi, Hemşirelik Yüksekokulu, İstanbul,Türkiye E-mail: gulcank_87@hotmail.com Telefon:0534-5943237.

Başvuru Tarihi: 18.02.2021 Kabul Tarihi: 15.06 .2021 Yayınlanma Tarihi: 25.06.2021

Atf İçin: Gülcan KENDIRKIRAN, Azize Gözde ATAKOĞLU, Deniz KAYA MERAL, Psikiyatri Hemşireliğinde İnovasyon ve Evde Hasta Takibi Innovation and Home Follow-up in Psychiatric Nursing, 2021;5(2):119-125

Not: Çalışma, 27-28 Eylül 2020 tarihleri arasında 2. Uluslararası Sağlık Bilimleri ve İnovasyon Kongresi'nde sözel bildiri olarak sunulmuş ve bildiri özeti kongre özet kitabında yayınlanmıştır.

\title{
Psikiyatri Hemşireliğinde İnovasyon ve Evde Hasta
} Takibi

\author{
Innovation and Home Follow-up in Psychiatric Nursing
}

Gülcan Kendirkıran ${ }^{1}$, (iD) Azize Gözde Atakoğlu², (iD Deniz Kaya Meral ${ }^{1}$

\section{Öz}

Bu çalışma, psikiyatri hemşireliğinde kullanılan inovasyon yöntemleri ve bu yöntemlerin evde hasta takibine katkısını incelemek amacıyla yapılmıştır. Bu derlemede, Google Akademik, Pubmed, Science Direct, Ulakbim gibi veri tabanları taranarak elde edilen psikiyatri hemşireliğinde inovasyon ve evde hasta takibine yönelik yapılmış çalışmalara yer verilmiştir. Hızla gelişen teknoloji, farklılaşan yaşam koşulları ve hastalık oranlarındaki artış sağlık hizmetlerinde yenilikler yapılması gerekliliğini getirmiştir. Uluslararası Hemşireler Birliği (International Council of Nurses-ICN), sağlık alanındaki yenilikçi uygulamaların geliştirilmesi ve desteklenmesi amacıyla Avrupa Birliği işbirliğiyle 2009 yılını inovasyon yılı olarak ilan etmiştir. Çocuk, ergen, genç, yaşlı her yaş grubundaki hasta ve hasta yakını hastane ortamını güvenilir görmekte fakat eve gidince tedirginlik ve anksiyete yaşamaktadır. Ulusal ve uluslararası platformlarda sağlık uygulamaları ve hasta takipleri, hemşireler tarafından sadece hastane ortamında değil, teknolojik cihazların hasta kullanımına uygunluğu da göz önünde bulundurularak uzaktan bağlanma ile evden de yürütülmesi ve hasta bireylerle yakınlarının desteklenmesi yönünde ilerlemektedir. Ruh sağlığı ve psikiyatri hemşireleri de hem hastane ortamında hasta bakım ve tedavileri ile hem de taburculuk sonrası telefon aracılığı ile hasta ve yakınları ile görüşmekte ve hastanın alevlenme dönemlerinin başlayacağı ya da başladığı süreçte neler yapılması gerektiği konusunda hasta ve hasta yakınlarını bilgilendirmektedir. Böylece hasta/hasta yakını hastane ortamında olmasa bile ani gelişecek durumlar karşısında hazırlıklı olmakta ve hemşirelere güvenerek stres yaşamamaktadırlar. Psikiyatri hemşirelerinin sadece hastanede değil, hastane dışı ev takiplerinde hem telefon hem de diğer teknolojik cihazlar ile daha sık görev alması önerilmektedir.

Anahtar Kelimeler: evde hasta takibi; inovasyon; psikiyatri hemşireliği; telehemşirelik

\section{ABSTRACT}

This study was conducted with the aim of investigating the innovation methods used in psychiatric nursing and the contribution of these methods on patient follow-up at home. This article includes studies on innovation and patient follow-up at home for psychiatric nursing which were obtained by searching databases such as Google Scholar, Pubmed, Science Direct and Ulakbim. Fast-growing technology, different lifestyles and the increase in disease rates required innovations in healthcare services. International Council of Nurses (ICN), in cooperation with European Union, has declared the year 2009 as the year of innovation in order to develop and support innovative healthcare applications. Patients and their relatives from every age (children, teenagers, young people, old people) see hospitals as safe environments yet, they experience anxiety and nervousness when they go home. In both national and international platforms, healthcare applications and patient follow-ups are not carried out only by nurses at hospitals, but also at home by remote connection by considering the suitability of the device for patient use. Patients and their relatives receive support during this period. Psychiatric nurses stay in contact with the patient and their relatives by phones after discharge in addition to providing care and treatment for them at the hospital. They also inform the patients and their relatives about what to do before or during the exacerbation of the disease. Thereby, patients/relatives become prepared for the emergency situations even if they are not at the hospital and trusting the nurses makes them stress-free. It is recommended that, in addition to hospitals, psychiatric nurses should take more charge in home follow-ups by both phones and other technological devices.

Keywords: patient follow-up at home; innovation; psychiatric nursing; telenursing 
İnovasyon (innovation), Latince "innovatus" kelimesinden türemiş olup Türkçe literatürde, "yenilik, yenilikçilik, yenilenme" ve Türk Dil Kurumu (TDK) (2007) tarafindan üretilen "yenileşim" kelimeleri kullanılmaktadır (1). İnovasyonun ifade ettiği anlamlar sadece teknoloji ile sınırlı kalmayıp bireysel, yönetsel, üretim ve pazarlama alanlarındaki yenilikleri de kapsamaktadır (2). Ülkelerin, hem kalınma güçlerini arttırmaları hem de rakiplerin giderek arttğı piyasada varlıklarını sürdürebilmeleri için inovasyon büyük önem taşımaktadır (3). Tüm inovasyon çeşitleri sağlık sektörünün merkezi olan hastanelerde, sürekliliklerini devam ettirebilme, sağlık personelinin ve hastaların ihtiyaçlarını karşılayabilme konusunda aktif olarak yer bulmakta ve bu doğrultuda da hastaneler inovatif olmak zorundadırlar (4). Genel bakış açısıyla sağıık alanına ve özel bakış açısıyla da hemşirelikte inovasyon ile birlikte yeni yaklaşımlar, teknolojiler ve çalışma biçimleri geliştirilmektedir (5). Sosyoekonomik durumlar, siyasi süreçler ve teknolojik gelişmeler ile birlikte ruh sağlığı ve psikiyatri hemşiresinin de rolleri değişmekte ve hastalarla etkileşim halinde bulunabilmek için inovasyona ihtiyaç duymaktadır $(6,7)$.

Günümüz şartları doğrultusunda hem hemşireler için hem de psikiyatri hastaları ve yakınları için inovasyon kullanımı sosyal hayatı ve iş hayatını daha kolay hale getirebilmekte, alevlenme ve öncü belirtilerin erken süreçte fark edilmesi ile durum karşısında uygun iletişim ya da müdahaleler belirlenebilmektedir. Bu doğrultuda, psikiyatri hemşireliğinde kullanılan inovasyon yöntemleri ve bu yöntemlerin evde hasta takibine katkısını incelemek amacıyla 2012-2020 yılları arasını kapsayacak şekilde Google Akademik, Pubmed, Science Direct, Ulakbim veri tabanları taranarak elde edilen psikiyatri hemşireliğinde inovasyon ve evde hasta takibine yönelik çalışmalara yer verilmiştir.

\section{Hemşirelikte İnovasyon Kullanımı}

Gelişen teknoloji ile birlikte sağlık alanında sürekli yenilikler ve değişiklikler meydana gelmektedir (8). Sağlıkta bakıma yönelik hizmetler maliyet açısında artış göstermekte olup bu durum sağlık kurumlarında etkili, ekonomik ve hasta merkezli bakım geliştirebilmek için inovasyon uygulamalarına yönelmeyi gerektirmektedir (9). Hemşirelikte, "yenilik" ve "yenilikçi yaklaşım" terimleri, özellikle bireyler/gruplar tarafindan yeni bir şey geliştirdiğinde veya mevcut uygulamaları geliştirdiğinde kullanılmaktadır (10). Uluslararası Hemşireler Birliği (International Council of Nurses-ICN) (2009) raporunda hemşirelikte inovasyon kullanımının önemini vurgulamış olup sağlık alanında inovasyon kullanımını arttırmak ve geliştirmek amacıyla Avrupa Birliği ile işbirliği içerisinde 2009 yılını inovasyon yılı ilan etmiştir $(4,5)$. Sağlık çalışanları inovasyonu yaygın ve etkili kullanan gruptur ve İngiltere'de, hemşirelerin çalışma ve bakım konusunda inovasyon kullanımlarını ve katkılarını ödüllendirmek amacıyla 27 yıldır "Hemşirelik Haberleri Ödülleri (Nursing Times Awards)" verilmektedir (11). Hemşireler, sağlık hizmetleri sunumunda verimli olmak ve beklenen sonuçları elde edebilmek için yenilikleri takip etmek ve inovasyon sürecini kendi çalışma birimlerine entegre etmek zorundadırlar (2). Sağlık hizmetlerinde teknolojinin kullanımı hemşireleri de etkilemekte ve uzak mesafedeki bireylere erişimi sağlayabilmek ve karmaşık sağlık sorunlarının bulunduğu süreçlerde, hemşireler bireylerin bakımını sağlamak ve sürekli hale getirebilmek için tele-sağlık, tele-hemşirelik teknolojilerini aktif olarak kullanma gereği duymaktadır (12). Ancak, iş temposunun yoğun olması ve hemşirelerin sürekli iş yetiştirme telaşının bulunması, kurumlarda kat kuralların olması nedeni ile hemşirelerin inovatif düşünme ve inovatif girişimler geliştirme becerileri engellenmekte ya da olumsuz yönde etkilenmektedir (3). Aynı zamanda da yeni bilgi öğrenme ve uygulama sürecinde hemşirelerin yeterli oranda araştırma yapabilme ve araştırma sonuçlarını kullanabilme becerilerinin olmaması, inovatif teknolojilere ve uygulamalara karşı direnç geliştirmelerine neden olabilmektedir (5).

Literatürde tanımlanan inovasyon müdahaleleri, hemşirelerin klinik araştırma yeteneklerini geliştirerek özgüvenlerini artırır ve mesleki eğitimde değer yaratır (13). Çoğu sağlık hizmeti kuruluşu, hemşireleri yenilikçi fikirler üretme ve geliştirme, fikirleri klinik araştrrmaya taşıma veya yeniliği klinik uygulamaya yayma konusunda güçlendirmek için gerekli inovatif alt yapıya veya kaynaklara sahip olmayabilir. Bu doğrultuda hemşireler, altyapı bileşenlerini ve temel desteği içeren bir hemşirelik inovasyon merkezi geliştirerek ekiplerini inovasyonun aktif kullanımı konusunda teşvik edebilirler (10).

\section{Ruh Sağıı̆ı Hizmetlerinde Kullanılan İnovasyon}

Ruh sağlığı alanında kullanılan inovasyon çalışmalarına bakıldığında sağıı hizmetleri, cep telefonları da dahil olmak üzere çeşitli farklı özelliklerdeki cihazlar aracılığı ile internet üzerinden elektronik yollarla sağlanmakta ve böylece hizmetlerin daha esnek bir şekilde sunulmasını ve bireysel hasta ihtiyaçlarına göre uyarlanmasını sağlayarak ruh sağlığı ve tedaviye erişimi büyük ölçüde artrabilir. Sensör teknolojisi, online terapi ve uzaktan video muayenesi ve aplikasyonlar (uygulamalar) hastaların katılımını sağlamak ve güçlendirmek ve akıl sağlığı sorunları için hem değerlendirme hem de müdahaleye yeni yaklaşımlar oluşturmak için gerçek firsatlar sunmaktadır (14). Video konferanslar tele-psikiyatride en yaygın kullanılan yöntemlerden biri olup, sağlık profesyonelleri uzaktaki hastalarını güvenli video ve ses akış sistemleri ile takip edebilmekte ve uzaktan klinik ruhsal bakım sağlayabilmektedir (15).

Web tabanlı destek grupları: Kurulan sitede kullanıcılar birbirleriyle iletişim kurabiliyor,
sağ lığı uzmanları tarafindan psikoeğitim programı ve oturumlar yürütülüyor (7, 14).
Tele sağlık hizmeti: Ruh sağlığı profesyonelleri tarafindan telefon ve video konferans aracılığıyla danışmanlık hizmeti
sunmaktadırlar(14). Telefontemelliuygulamalarhemşirelerinaktifolarakyeraldığıvehastalaraçısından etkiliolanyöntemdir(7).
Illaç temini ve yönetimi: Psikiyatri hastalarının düzenli ve uzun süreli ilaç kullanmalarıgerekmektedir. Illaç yönetimi (ilaç
temini, kullanım zamanı, dozu vb.) için bazı ilaçfirmaları hastalara kullanım kolaylığı sağlamaktadır. Firmanın web sitesinden kayıt


sağlayan hastaların ilaçları kullanım şekline göre evlerinegönderilmektedir. Kayıt için hastalardan sistemereçete, doktor, sigortave ödemebilgisiistenmektedir(14). Buyöntem dahilindehastabireyveailelerihemşireleriledeetkileşimhalindebulunmaktadırlar(7).

Uygulamalar (App): Tipik olarak, bu uygulamalar bir semptom izleyici ve günlük işlevi, randevu ve ilaç hatırlatıcıları ve motivasyonel uyarıları içerir. Bunun yanı sıra kullanıcıyı otomatik olarak bir ruh sağlığı uzmanına bağlar. Hastalar, terapistlerinin normal çalışma saatleri dışında profesyonel desteğe erişmek için bu uygulamayı kullanabilir (14).

\section{Psikiyatri Hemşireliğinde İnovasyonun Yeri}

Psikiyatrik hastalıkların çoğu, kronik ve tekrarlayıcı olmaları nedeniyle erken teşhis ve müdahale için multidisipliner bir yaklaşıma ihtiyaç duymaktadır. Ruhsal hastalığı olan bireylerin bakımı ile ilgili ortaya çıkan sorunları ele almak için yeni bakım modelleri zorunludur. Sistemin, mevcut duruma meydan okuyacak ve değişen bakım hizmeti sunum modellerini araştıracak, rehberlik yapacak ve hasta haklarını savunacak enerjik ve yaratıcı hemşirelere ihtiyacı var. Dolayısıyla ruh sağlığı hemşireliğinde yenilik ve hayal gücünün benimsenmesi gerekmekte, bu doğrultuda gerçekleşecek olan değişimin kalıcılığı ancak ruh sağlığı hizmetlerinden sorumlu olan tüm disiplinlerin ortak çabası ile mümkündür (16).

Psikiyatri hemşireliği sadece birey ile değil, bireyin ailesi ve toplumun ruh sağlığının geliştirilmesinde, ruhsal hastalık ve buna bağlı ortaya çıkan sorunları önlemede, hastalıkla baş edebilme ve gerektiği durumlarda da bireylerin yaşamlarında anlam bulmada etkin rol oynamaktadır (6). Ruh sağlığı ve hastalıkları hemşirelerinin yaptıkları faaliyetler arasında kuram geliştirme, kuramları birbirleriyle birleştirme bulunmakla birlikte ruh sağlığı ve hastalıkları hemşirelerinde var olması beklenen karar verme ve kararı uygulama, durum analizi yapabilme, problemleri saptama ve çözüm üretebilme, alternatif çözümler üretebilme becerileri olduğu görülmektedir (8). Bu kapsamda inovasyonun kullanımı ruh sağlığı ve hastalıkları hemşirelerinin sahip oldukları tüm becerilerini rahatlıkla uygulamalarına olanak sağlayabilmektedir.

Tele-psikiyatri uygulamalarında aktif rol alan psikiyatri hemşireleri etkili iletişim kurma yetilerini kullanarak, sağlık bakımının niteliğine yön vermektedir $(17,18)$. Bu amaçla, tele-psikiyatri alanında hizmet sunumu gerçekleştirecek sağlık profesyonellerine teknik eğitim verilmesi ve uygulama ile ilgili tele-hemşirelik rehberlerinin oluşturulması gelişen bakım anlayışıyla paralellik gösterecektir (19). Gerekli donanıma sahip hemşireler inovasyonu kullanarak hastalar ve aileleri ile hastane ortamında olmaları gerekmeden iletişim halinde olabilmektedirler (20). Inovasyon, özellikle yaşlı ve engelli bireylerin kısıtlanmış fiziksel kabiliyetleri dolayısıyla evde bakımında tercih edilen bir uygulamadır (21). Evde bulunan psikiyatri hastaları ve aileleri için inovatif yöntemlerden olan tele-psikiyatri, bireylerin evinde ya da gizlilik açısından kendilerini güvende hissedebilecekleri bir ortamda, kendi tayin ettikleri bir zamanda, çalışıyorlarsa iş yerinden izin almak zorunda kalmadan ve sağ ık kuruluşuna gelmeye bağlı damgalama endişesi yaşamadan uzaktan ruh sağlığı hizmeti alabilmesidir $(19,21)$.

\section{İnovasyon ve Evde Hasta Takibinin Önemi}

İnovasyonun kullanımı ile birlikte toplum temelli ruh sağlığı hizmetleri de artmaktadır. Toplum temelli ruh sağlığı hizmetleri hastaların kendi kültürel ortamlarında aile ve sosyal ortamlarından koparılmadan izlem, tedavi ve bakımlarının devamılı̆̆ını sağlamak, yaşamlarıyla ilgili sorumluluk almalarını sağlamak, hastalığa bağı işlevselliklerindeki azalmanın önüne geçmek, ruhsal sorunlarıyla baş etme becerileri geliştirmelerine yön vermek ve hastalık nedeniyle kaybettikleri toplumsal imajlarını tekrar kazandırabilmek amacıyla gerekli destek sistemlerinin uygulanmasıdır (22). Toplum ruh sağlığı hemşireleri de birey ve ailelerine bakım, eğitim, danışmanlık, vaka yönetimi ve terapi gibi girişimlerle psikososyal davranışsal sağlık hizmetleri sunmaktadır $(22,23)$. Ülkemizde ve dünya genelinde ruh sağlığı hizmetleri hastane temelli, toplum temelli ve toplum-hastane dengeli modeller ile yürütülmektedir (23).

Toplum ruh sağlığı hizmetlerinde bireye yönelik yapılan hastane içi ve ayaktan tedavi ile evde bakımın bütünleştirilmesi yalnızca uygulayıcı disiplinler için değil aynı zamanda hasta ve ailesi için de önem teşkil etmektedir (23). Günümüzde ruhsal bozukluğu olan bireylerin toplum temelli uygulamalar ile toplumda sosyalleşmeleri, toplumdan dışlanmadan tedavi ve bakımlarının yapılması, hastanede yatı̧s sürelerinin kısa tutulması ve tekrarlı hasta yatşları önlenmesi, topluma kazandırılmaları hedeflenmektedir (6). Bu kapsamda ülkemizde 2006 yılında "Sağlık Bakanlığı" tarafindan "Türkiye Cumhuriyeti Ruh Sağlığı Politikası" yayımlanarak ruh sağlığı uygulamalarında toplum temelli hareket edilmesi vurgulanmış akabinde "Toplum Temelli Ruh Sağlığı Hizmet Modeli"nin ülkemize yerleşmesinin hedeflendiği “Ulusal Ruh Sağlığı Eylem Planı (2011)" oluşturularak, 2023 yılına kadar gerçekleştirilmesi planlanan temel hedef ve stratejiler oluşturulmuştur (24).

2011 yılında "Sağlıkta Dönüşüm Programı" kapsamında “Evde Sağılı Hizmetleri” kavramı ile mobil sağlık hizmetleri yürütülmeye başlanmış olup, bu uygulama ile ülkemizde toplum temelli bakım modeli içerisinde yer alan evde bakım modeline geçilmiştir (25). Günümüzde ruhsal ve fiziksel bozukluklara bağlı olarak hareket kısıtlılıkları bulunan, eve bağı/bağımlı olan, yeti yitimi ve sürekli bakıma ihtiyacı olan birey ve ailelerine sadece hastane ortamında sağlık bakım hizmetlerinin sunulması artık yetersiz kalmaktadır (26). Evde bakım hizmetleri başlangıçta sıklıkla fiziksel gereksinimlerin karşılanmasına yönelik başlamış olsa da, bireyin tüm yaşamı göz önüne alındığında bunun yeterli olmadığı, özellikle yeti yitimine sebep olan ruhsal bozuklukların bakım ve tedavisinde evde psikososyal müdahalelerin uygulanması gerektiği giderek önem kazanmaktadır (27). Evde bakım hizmetlerinde kullanılan internet, telefon, video konferans gibi telekomünikasyon araçları vasıtasıyla gerçekleştirilen psikososyal müdahaleler ile hastalık belirtilerinin sıklıklarının azalması, alevlenme ve öncü belirtilerin erken dönemde farkına varılması, kişiler arası ve sosyal ilişkilerde iyileşme, hasta ve ailelerinin yaşam kalitesinde artş ve tedavide maliyet düşüklüğü hedeflenmektedir (19). 


\section{Tele-Sağlık Hizmetleri}

Dünyada olduğu gibi ülkemizde de kronik hastalıkların ve yaşlı nüfusun hızlı artı̧ı ile birlikte sağlık hizmetlerine ihtiyaç duyan bireylerin sayısı artmış olup, teknolojive bilişimdeki hızlı gelişim de beraberinde sağlık hizmetlerinin sunumunda bir takım yenilikleryapılmasınıgerektirmiştir(28). Bilgi-iletişimteknolojisindekihızlıdeğişim, bireylerinsağlıkhizmetsunumunaduydukları ihtiyaçlarını her zaman ve her yerden kesintisiz karşılama gereksinimini doğurmuştur (18). Bu değişim, sağlık hizmet sunumunda da etkisini göstererek tele-tıp, tele-hemşirelik gibi yeni sağılı sistemlerinin geliştirilmesini ve uygulanmasını teşvik etmiştir (19).

Dünya Sağlık Örgütü (DSÖ), akıllı cep telefonları, tablet bilgisayarlar, dijital hasta görüntüleme cihazları ve diğer kablosuz mobil iletişim araçlarının kullanılarak, hasta bireylerin sağlık bilgilerinin takibinin yapılmasını ve hizmet sunumun da kullanılmasını desteklemektedir (29). Sağlık hizmetlerinin sunumunda dünya genelinde ve ülkemizde maliyetlerin düşürülmesi gündemde olduğu için cep telefonu tabanlı (mSağlık) hayati bulguların takibini kolaylaştıran mobil sağıı hizmetleri popülerlik kazanmıştır (30, 31).

Tele-sağlık, bireylerin sağlığını geliştirmek, kırsal kesimde yaşayan ve mesafeye bağlı sağlık hizmetine ulaşmada güçlük yaşayan halkın adil hizmete erişebilmelerini sağlamak, sağlık harcamalarındaki maliyetleri düşürmek ve teşhis, izlem, araştırma ve yeterli iletişimi sağlamak üzere sağlık profesyonelleri tarafindan dijital teknolojiler aracılığıyla sunulan uygulamalardır (31). Tele-tıp uygulamaları ise tele-psikiyatri, tele-evde bakım, tele-dermatoloji, tele-cerrahi, telekardiyoloji, tele-oftalmoloji, tele-radyoloji, tele-patoloji, tele-konsültasyon gibi uygulamalarda kullanılmaktadır (32).

\section{Psikiyatride Tele-Hemşirelik Uygulamaları}

Tele-hemşirelik, telefon, bilgisayar ve internet gibi telekomünikasyon araçlarıvasıtasıyla mesafeleri ortadan kaldırarak bireylere etkili hemşirelik bakım hizmetlerinin sunulmasıdır $(33,34)$. Evde bakım hizmetlerinde tele-hemşirelik uygulamasının kullanılmasındaki en önemli nedenler; kronik hastalıkları nedeniyle uzun dönem bakım ve takip gerektiren hastalara verimli hizmet sunmak, fiziksel koşullar ve mesafe nedeniyle sağlık hizmetinden istifade edemeyen bireylere hizmete erişim kolaylığı sağlamak, hastane sonrası bakım ve takibin efektif yürütülebilmesini sağlamak ve hem hastaların hem de yakınlarının sağlanan mobil izlem ve destek hizmetleriyle yaşam kalitesinin arttrılması olarak sıralanabilir (26). Tele-hemşirelikte profesyonel hemşirelik hizmetleri mesleğin doğası değiştirilmeden hemşirelik süreci çerçevesinde devam ettirilmektedir (18). Dünya genelinde psikiyatrik hastalığı bulunan bireylerin takibi ve tedavisi için çeşitli mobil uygulamalar da geliştirilmekte ve hastaların elde ettikleri hemşire ve diğer sağlık profesyonellerine erişim rahatlığı nedeni ile hastalar üzerinde olumlu etkileri olduğu belirtilmektedir (35). Hemşirelerin eğitici rolü de göz önüne alındığında, bilgi, danışmanlık, yönlendirme ve destek hizmetleri sağlanırken hemşireliğin özü olarak kabul edilen terapötik hasta-hemşire ilişkisi teknolojik gereçler ile yürütülmektedir (36). Özellikle uzaktan takip uygulamalarından telefon sistemleri düşük maliyetli olması sebebiyle tercih edilmektedir (37).

Evde bakımda tele-hemşirelik uygulaması, bireylerin kendi bakımlarına aktif katlarak bakımlarını yönetmeleri ve sorumluluk alabilmelerini sağlamaktadır (26). Sağlık profesyonelleri açısından da hizmet sunumunda ekip arasında haberleşme ve koordinasyonu sağlaması, uygulamanın diğer avantajları arasında sayılmaktadır (33). Tüm bunlarla beraber gizlilik, hasta güvenliği, tele-hemşirelik teknolojisinin kurulumu ile donanım maliyetleri, bu alanda hizmet verecek sağlık çalışanlarının eğitimlerinin maliyeti, hastaların teknolojik cihazları alacak maddi güçlerinin olmaması, cihaz kullanımını bilmemeleri ve özellikle sözsüz iletişimdeki engeller uygulamanın sınırıııkları olarak düşünülmektedir $(19,21)$.

Günümüzde ruhsal bozuklukların yaygınlığı dünyada ve ülkemizde giderek artmakta ve bireylerin büyük bir çoğunluğu gerek damgalanma korkusu, gerek bilgi eksikliği gerekse de sosyal ortamlara girmekten çekinmeleri sebebiyle tedaviye ulaşamamakta ya da tedavi sonrası yeterli izlemin yapılamaması sebebiyle tedavileri kesilmektedir (29). Sonuçta çeşitli engellerle tedavi altnna alınamamış bireyler toplumdan uzaklaşmakta, iş gücü kaybı yaşamakta ve dolayısıyla çeşitli finansal ve sosyal sorunlar yaşamaktadır (18).

Ruhsal bozukluğu olan bireylerin kendi sosyal ortamlarından koparılmadan, toplum temelli tedavi ilkeleri çerçevesinde hizmet almalarını desteklemek amacıyla son yıllarda elektronik temelli tedavi ve bakım modelleri geliştirilmiş ve psikiyatri alanına yansımaları olmuştur (17). Tele-psikiyatri, tele-tıp hizmetlerinin ruh sağlığı hizmetlerine uyarlanmış biçimidir (18). Tele-psikiyatri hizmetleri; evde tele-psikiyatri, adli tele-psikiyatri, acil durum tele-psikiyatrisi, rutin tele-psikiyatri uygulamaları olarak sunulan hizmet alanına göre alt bölümlere ayrılmaktadır (21). Tele-psikiyatride kullanılan taşınabilir bilgisayarlar, telefon, video konferans, internet, radyo, sms, aplikasyon uygulamaları, monitör, ev tipi sağlık araçları ve diğer ek cihazlarla bağlanılan iletişim sistemleri ile çift yönlü, anında ve etkili bakım, tedavi ve izlem sağlanabilmektedir $(18,19)$. Aynı şekilde hastalar da sağıık çalışanları ile görsel-işitsel teknolojik araçlar vasıtasıyla eş zamanlı iletişime geçebilmektedir (18).

\section{Covid-19 Pandemisi ve İnovasyon}

Kitlesel bir afet olan Covid-19 bulaştrıcılık düzeyinin çok yüksek olması, hemen hemen tüm ülkelere yayılmış olması ve sosyoekonomik yaşamı fazlaca etkilemiş olması gibi sebeplerden ötürü, ülkelerin sağlık sistemine hem ekonomik hem de insan gücü anlamında ciddi bir yük getirmiştir (38). Sosyal izolasyon nedeniyle toplum yaşamında ciddi değişiklikleri beraberinde getiren pandemi sürecinde sağlık kuruluşlarına ulaşamayan ya da başvurmaktan kaçınan hastalara uzaktan görüntülü konuşma ya da telefon aracılığıyla sağlık hizmeti sunumuna devam edilmiştir (39). Öte yandan geniş çaplı Covid-19 taraması yapılması, test merkezleri ve tanı alan bireylerle iletişimin sağlanması ve hasta olan kişilerin takibini sağlamak için, web tabanlı program, 
videolu görüşme sistemleri ve akıllı telefon uygulamaları gibi tele-sağlık uygulamaları kullanılmaya başlanmıştı $(40,41)$.

Covid-19 ilişkili, kişinin kendisi ve yakınlarına bulaş riski tehdidi, sosyal izolasyon, belirsizlik, çaresizlik, çalışamama, ekonomik kayıplar, medyada yer alan olumsuz haberler ve stres bireysel ve toplumsal düzeyde kaygı seviyesinin artmasına sebep olmakta ve ruh sağlığını olumsuz etkilemektedir (41). Kronik ruhsal bozukluğu olan hastaların rutin kontrol ve sağlık danışmanlıklarının devam ettirilmesini sağlamasının yanı sıra pandemi ile ilişkili ruhsal sıkıntılara destek sunmak amacıyla telefonla sesli arama, görüntülü görüşme, video konferans ve online toplantlar gibi inovasyon uygulamaları pandemi döneminde ivme kazanmıştır (40).

ÜlkemizdeCovid-19PandemiSürecinde RuhsalSıkıntlarıGidermeye YönelikOluşturulan Hatlarve Online Uygulamalar Ülkemizde koronavirüs pandemi sürecinde Covid-19 pozitif tanısı almış bireyler, yakınını kaybetmiş olanlar, psikiyatrik tedavisi yarıda kalan hastalar, alkol-madde kullanım bozukluğu ile kronik hastalığı olanlar ve 65 yaş üstü bireyler öncelikli olmak üzere, ruhsal destek ihtiyacı hisseden tüm bireylere hizmet vermek için ruhsal destek programları, telefon hatları ve mobil uygulama sistemleri oluşturulmuştur (42). Oluşturulan programlarla bireyler intiyaçlarına yönelik ilgili sağlık profesyonellerine yönlendirilerek telefonla veya gerektiğinde online terapi hizmetinden faydalanmaktadır (40). Bu uygulamalar için oluşturulan ekip içerisinde ruh sağlığı ve psikiyatri hemşireleri de aktif olarak görev almaktadırlar.

Ülkemizde, Covid-19 pandemi sürecinde inovasyon kullanımına örnek olarak hizmet veren ve bireylere ruhsal destek sağlayan telefon hatları ve mobil uygulamalar; "Koronavirüs Destek Programı (KORDEP)" Çevirimiçi Destek Hatt (0850 30500 34), Türkiye "Psikiyatri Derneği Sağlık Çalışanlarına Ruhsal Destek (RUHSAD)" Hatt (0850 5326676 ), “Koronavirüs Tele-Rehabilitasyon Destek Programı (KOREH)” Hatt (0850 30556 67) şeklinde sıralanabilir (43, 44, 45).

"Koronavirüs Online Ruhsal Destek Programı (KORDEP)", pandemi sürecinde gelişen ve oluşabilecek ruhsal sıkıntıların çözümü için Sağlık Bakanlığı İstanbul ì Sağlık Müdürlüğü tarafindan geliştirilen, telefonla ve gerektiğinde web üzerinden online terapi hizmeti de veren bir ruhsal destek programıdır (43).

"Ruh Sağlığı Destek Sistemi (RUHSAD) Uygulaması", Sağlık Bakanlığı tarafindan geliştirilen, Covid-19 nedeniyle karantinada olan, test sonucu pozitif tespit edilen, yakını yoğun bakım ünitesinde takip edilen, Covid-19 klinik ve yoğun bakım ünitelerinde görev yapan, kaygı düzeyi yüksek ve ruh sağlığı desteğine ihtiyaç duyan tüm sağlık çalışanlarının kendisi ve çocukları için görüntülü görüşme imkânı tanıyan bir mobil uygulamadır (45).

"Koronavirüs Tele-Rehabilitasyon Destek Programı (KOREH)", "Sağlık Bakanlığı i̇stanbul ill Sağlık Müdürlüğü" tarafindan koronavirüsten etkilenen/etkilenmeyen, karantina nedeniyle evde kalmak durumunda kalan genç/yaşlı tüm bireyler ile kronik hastalıkları olan hastaneye ulaşamayan bireyler için geliştirilmiş, fizyoterapist ve fizik tedavi uzman hekimleri eşliğinde gerçekleştirilen bir telefonla destek programıdır (44).

\section{SONUÇ ve ÖNERILER}

Teknolojinin hızla gelişmesi ve yaşam şartlarının farklılaşması, sunulan sağlık hizmetlerinde yenilikler yapılmasını gerekli hale getirmiştir. Ruh sağlığı ve psikiyatri hemşireleri de hem hastane ortamında hasta bakım ve tedavileri ile hem de taburculuk sonrasında teknolojik cihazlarla özellikle de telefon aracılığı ile hasta ve yakınları ile görüşmekte ve hastanın alevlenme dönemlerinin başlayacağı ya da başladığı süreçte neler yapılması gerektiği konusunda hasta ve hasta yakınlarını bilgilendirmektedir. En kolay erişim sağlanabilen telefon desteğinin kullanılması, ilaç tedavisine uyumu iyileştirmek ve semptomların şiddetini ve hastane başvurularını azaltmak için etkilidir. Böylece hasta/hasta yakını hastane ortamında olmasa bile ani gelişecek durumlar karşısında hazırlıklı olmakta ve hemşirelere her an ulaşabilecekleri için güven duymakta, stres yaşamamaktadırlar. Sadece kronik hastalığa sahip birey ve ailesi için değil yaşanan salgın, doğal afet gibi durumlarda da aktif rol almaktadır. Ancak buna ek olarak inovasyon konusunda yetkin olan ruh sağlığı ve psikiyatri hemşirelerinin de iş yükünde artı̧ olacağı belirtilmektedir.

Psikiyatri hemşirelerinin sadece hastanede değil, hastane dışı ev takiplerinde hem telefon hem de diğer teknolojik cihazlar ile daha sık görev alması, ruh sağlığı ve psikiyatri hemşirelerinin tamamına inovatif yaklaşımın benimsetilmesi ve aktif kullanıma teşvik edilmeleri önerilmektedir.

\section{BILDIRIMLER}

Çıkar Çatışması: Yazarlar arasında çıkar çatışması yoktur.

Finansal Destek: Herhangi bir kurumdan maddi destek alınmamıştır.

Etik Kurul İzni: Çalışmada literatür üzerinden tarama yapıp yazım işlemini gerçekleştirildiği için herhangi bir etik kurul izni gerekmemektedir. 


\section{KAYNAKLAR}

1. Şahbaz A, İnovasyon ve girişimcilik kavramlarının karşılıklı etkileşimi, Girişimcilik İnovasyon ve Pazarlama Araştırmaları Dergisi, 2017:1(1);20-38.

2. Eriş H, Kabalcıoğlu F, İnovasyonun çalışma performansı üzerine etkisi, Avrupa Bilim ve Teknoloji Dergisi, 2020:18;76-80. DOI: 10.31590/ejosat.662069

3. Özbey H, Başdaş Ö, Hemşirelikte inovasyon, Erciyes Üniversitesi Sağlık Bilimleri Fakültesi Dergisi, 2018:5(1);1-7.

4. Kartal H, Kantek F, Hemşirelikte inovasyon örnekleri. Sağlık ve Hemşirelikte Yönetim Dergisi, 2018:5(1);57-63. DOI: 10.5222/SHYD.2018.057

5. Dil S, Uzun M, Aykanat B, Hemşirelik eğitiminde inovasyon, International Journal of Human Sciences, 2012:9(2);12171228.

6. Yılmaz M, Özcan A, Psikiyatri hemşireliğinin geleceği, Mersin Üniversitesi Sağlık Bilimleri Dergisi, 2016:9(1);53-9.

7. Lawes-Wickwar S, McBain H, Mulligan K, Application and effectiveness of telehealth to support severe mental illness management: Systematic Review. JMIR Mental Health, 2018: 5(4);1-13. DOI: 10.2196/mental.8816

8. Çam MO, Öztürk Turgut $E$, Ruh sağlığı ve hastalıkları hemşireliğinde yaratııılık, Psikiyatri Hemşireliği Dergisi, 2015:6(2);100-103. DOI: 10.5505/phd.2015.26349

9. Weng R. H, Chen W. P, Huang C. Y, Hung C. H, Hsu CT, Can nurse innovation improve customer perception of service quality and experience? Molecular Ecology, 2016:25(1);1950-1961. DOI: 10.1111/jocn.13214

10. Albert NM, Operationalizing a nursing innovation center within a health care system, Nursing Administration Quarterly, 2018:42(1);43-53. DOI: 10.1097/NAQ.0000000000000266

11. Nursing Times Awards, https://awards.nursingtimes.net, 2020 (Erişim tarihi: 8 Eylül 2020).

12. Uslu E, Buldukoğlu K, Tele-Hemşirelik uygulamalarının şizofreni hastalarııın bakımına etkisi: Sistematik Derleme, Türk Psikiyatri Dergisi, 2016:27(1);47-56.

13. Nedder MM, Levine SA, Galligan C, Avery KR, Eagan Bengston E, Reilly KM, Blogging as an innovative method of peer-topeer educational sharing, Critical Care Nurse, 2017:37(1);1-9. DOI: 10.4037/ccn2017642

14. Hollis C, Morriss R, Martin J, Amani S, Cotton R, Denis M, Lewis S, Technological innovations in mental healthcare: harnessing the digital revolution, The British Journal of Psychiatry, 2015:206(4);263-265. DOI: 10.1192/bjp. bp.113.142612

15. Wang L, Alexander CA, Telepsychiatry: technology progress, challenges and language and transcultural issues, Journal of Translational Medicine and Developmental Disorders, 2014:1(1);1-11. DOI: 10.12691/JTMDD-1-1-1

16. Procter N, Amar AF, Towards innovation and a partnership future for mental health nursing, Contemporary Nurse, 2014:34(2);131-133. DOI: 10.1080/10376178.2010.11002419

17. Bjorkman A, Erikson MS, When all other doors are closed: telenurses' experiences of encounteringcare seekers with mental illnesses, International Journal of Mental Health Nursing, 2018:27;1392-1400.

18. Özgüç S, Tanrıverdi D, Tele-psikiyatri. Psikiyatri Hemşireliği Dergisi, 2019:10(4);302-308. DOI: 10.14744/phd.2019.37232

19. Çam MO, Kaçmaz ED, Tele sağlık uygulamaları ve psikiyatri hemşireliğinde kullanımı, Türkiye Klinikleri Journal of Nursing Sciences, 2018:10(4);363-369. DOI: 10.5336/nurses.2018-59821

20. Eriksson I, Ek K, Jansson S, Sjöström U, Larsson M, To feel emotional concern: A qualitative interview study to explore telephone nurses' experiences of difficult calls, Nursing Open, 2019:6;842-848. DOI: 10.1002/nop2.264

21. Bal U, Yılmaz E, Tamam L, Çakmak S, Telepsikiyatri: şimdi ve burada, Psikiyatride Güncel Yaklaşımlar, 2015:7(2);136-148. DOI: $10.5455 /$ cap.20150320123914

22. Yıldırım A, Aşılar RH. Toplumda ruhsal bozuklukların yönetimi ve hemşirelik. Hacıhasanoğlu Aşılar R, editör. Kronik Hastalıklarda Bakımın Yönetimi ve Hemşirelik. 1. Baskı. Ankara: Türkiye Klinikleri, 2019. s. 85-92.

23. Çiçekoğlu P, Duran S. Dünyada ve Türkiye'de toplum temelli koruyucu ruh sağlığı hizmetleri. Ünsal Barlas G, editör. Toplum Ruh Sağlığı Hemşireliği. 1. Baskı. Ankara: Türkiye Klinikleri, 2018. s. 8-14.

24. Soygür H, Türkiye'de toplum ruh sağlığı merkezleri: Qua vadis?, Nöropsikiyatri Arşivi, 2016:53;1-3. DOI: 10.5152/ npa.2016.15022016

25. Işık O, Kandemir A, Erişen MA, Fidan C, Evde sağlık hizmeti alan hastaların profili ve sunulan hizmetin değerlendirilmesi, Hacettepe Sağlık İdaresi Dergisi, 2016:19(2);171-186.

26. Ersoy S, Yıldırım Y, Aykar FŞ, Fadıloğlu Ç, Hemşirelikte inovatif alan: evde bakımda telehemşirelik ve telesağıık, Acıbadem Üniversitesi Sağlık Bilimleri Dergisi, 2015:6(4);194-201. 
27. Kaya H, Özkan B, Evde bakımda kanıta dayalı Psikososyal müdahaleler, Yıldırım Beyazıt Üniversitesi Sağlık Bilimleri Fakültesi Hemşirelik E-Dergisi, 2014:2(2);1-8.

28. Akman $Y$, Mercan $Y$, Sağlık amaçlı internet kullanımı ve mobil sağlık uygulamaları üzerine bir araştırma, Kırklareli Üniversitesi Sosyal Bilimler Meslek Yüksekokulu Dergisi, 2020:1(1);66-76.

29. Ladea $\mathrm{M}$, Bran $\mathrm{M}$, Is the 21st century ready for a change in the psychiatric practice? The place of telepsychiatry in European and global telemedicine, Anul XII, 2016:44(1);28-30.

30. Weinstein RS, Krupinski EA, Doarn CR, Clinical examination component of telemedicine, telehealth, mHealth and connected health medical practices, Medical Clinics of North America, 2018:102(3);533-44. DOI: 10.1016/j. mcna.2018.01.002

31. Uysal B, Ulusinan E, Güncel dijital sağlık uygulamalarının incelenmesi, Selçuk Sağlık Dergisi, 2020:1;46-60.

32. Korkmaz S, Hoşman i, Sağlık sektöründe tele-tıp uygulamaları: tele-tıp uygulama boyutlarını içeren bir araştırma. Uluslararası Sağlık Yönetimi ve Stratejileri Araştırma Dergisi, 2018:4(3);251-263.

33. Barbosa IA, Silva KC, Silva VA, Silva MJP, The communication process in Telenursing: integrative review, Revista Brasileira de Enfermagem, 2016:69(4);718-25. DOI: 10.1590/0034-7167.2016690421i

34. Goudarzian M, Fallahi-Khoshknab M, Dalvandi A, Delbari A, Biglarian A, Effect of telenursing on levels of depression and anxiety in caregivers of patients with stroke: A randomized clinical trial, Iranian Journal of Nursing and Midwifery Research, 2018:23(4);248-52. DOI: 10.4103/ijnmr.IJNMR_242_16

35. Çetinkaya B, Uslu E, Parmak Ucundaki Bakım: Mobil Uygulama ve Şizofreni Hastalarının Bakımında Kullanımı, Acıbadem Üniversitesi Sağlık Bilimleri Dergisi, 2020:11(4);574-581. DOI: 10.31067/0.2020.309

36. Junior VDS, Mendes IAC, Mazzo A, Godoy S, Application of telenursing in nursing practice: an integrative literature review, Applied Nursing Research, 2016:29;254-60. DOI: 10.1016/j.apnr.2015.05.005

37. Zeev DB, Brian RM, Jonathan G, Razzano L, Pashka N, Song AEC et al., Mobile health (mHealth) versus clinic-based group intervention for people with serious mental illness: a randomized controlled trial, Psychiatric Services, 2018:69(9);97885. DOI: 10.1176/appi.ps. 201800063

38. Kahraman T, Koronavirüs hastalığı (COVID-19) pandemisi ve telerehabilitasyon, İzmir Katip Çelebi Sağlık Bilimleri Fakültesi Dergisi, 2020:5(2);87-92.

39. Moore MA, Munroe DD, COVID-19 brings about rapid changes in the telehealth landscape, Telemedicine and e-Health, 2020:1-3. DOI: $10.1089 /$ tmj.2020.0228

40. Çapacı M, Özkaya S, COVID-19 pandemi döneminde tele-tıp uygulamaları, Anadolu Kliniği Tıp Bilimleri Dergisi, 2020:25(1);260-62. DOI: 10.21673/anadoluklin.738672

41. Ulusoy S, Çelik Z, Covid-19 sürecinde internet tabanlı müdahaleler bir seçenek olabilir mi?, Bilişsel Davranışçı Psikoterapi ve Araştirmalar Dergisi, 2020:9(2);166-169. DOI: 10.5455/JCBPR.106343

42. Hiçdurmaz D, Özçetin YSÜ, COVID-19 pandemisinde ön safta çalışan hemşirelerin ruhsal sağlığının korunması ve ruhsal travmanın önlenmesi, Hacettepe Üniversitesi Hemşirelik Fakültesi Dergisi, 2020:7(Özel Sayı);1-7. DOI: 10.31125/ hunhemsire. 775531

43. T.C. Sağlık Bakanlığı İstanbul ilı Sağlık Müdürlüğü, Koronavirüs pandemisinde online ruhsal destek (KORDEP). https:// istanbulism.saglik.gov.tr/TR,180686/korona-virus-pandemisinde-online-ruhsal-destek.html (Ek'i) https://dosyaism. saglik.gov.tr/Eklenti/103059,web-gorselpdf.pdf?0, 2020a (Erişim tarihi: 8 Eylül 2020).

44. T.C. Sağlık Bakanlığı İstanbul i̇ Sağlık Müdürlüğü, Koronavirüs tele rehabilitasyon destek programı (KOREH). https:// istanbulism.saglik.gov.tr/TR,182256/istanbul-il-saglik-mudurlugu-koronavirus-tele-rehabilitasyon-destek-programikoreh.html, 2020b (Erişim tarihi: 8 Eylül 2020).

45. T.C. Sağlık Bakanlığı, Ruh sağlığı destek sistemi (RUHSAD) uygulaması. https://dosyamerkez.saglik.gov.tr/ Eklenti/37081,ruhsad uygulamasiustyazipdf.pdf?0\&_tag1=F5A16DDBE4FF19363630793070A8025A1C3BBE78 (Ek'i) https://play.google.com/store/apps/details?id=tr.gov.saglik.ruhsad\&gl=TR, 2020a (Erişim tarihi: 8 Eylül 2020). 